\title{
Optimization and Modelling of Turbidity Removal of Sewage using High-Gradient Magnetic Separation (HGMS) by Response Surface Methodology (RSM)
}

\author{
Nur Sumaiyyah Supian*, Johan Sohaili and Nur Farhan Zon \\ Department of Civil Engineering, School of Civil Engineering, Faculty of Engineering, Universiti Teknologi \\ Malaysia, 81310 UTM, Johor Bahru, Johor, Malaysia
}

\begin{abstract}
Endless industrial development and growing society occasionally create an enormous volume of wastewater, which leads to some issues on wastewater treatment. Existing conventional screening processes have various limitations and drawbacks. Therefore, this study investigated the use of a combination of non-corrosive stainless steel wool and a permanent magnet to increase magnetic gradient, hence reducing suspended matter in sewage through turbidity test. An approach for optimizing the reduction of suspended matter through turbidity analysis was conducted using central composite design (CCD) under response surface methodology (RSM). Three critical independent variables, such as magnet strength, circulation time, and steel wool, and turbidity removal as the response, were further studied to analyze their interaction effects. As a result, an optimal value of turbidity removal was found at $90.3 \%$ under the specified optimum conditions of magnet strength of $245 \mathrm{mT}, 116 \mathrm{~g}$ of non-corrosive stainless steel wool, and $16 \mathrm{~h}$ of circulation time. Statistical analysis had shown that the magnet strength, circulation time, and steel

ARTICLE INFO

Article history:

Received: 27 May 2020

Accepted: 10 August 2020

Published: 21 October 2020

DOI: https://doi.org/10.47836/pjst.28.4.13

E-mail addresses:

maya_viaxzey89@yahoo.com (Nur Sumaiyyah Supian)

johansohaili@utm.my (Johan Sohaili)

nur_farhan02@yahoo.com (Nur Farhan Zon)

*Corresponding author

wool significantly affected the turbidity removal performance. Furthermore, design of experiment was significantly verified by a small range of error between predicted and actual data. Consequently, a higher gradient of magnetic separation was proven to effectively remove suspended matter using inexpensive non-corrosive stainless steel wool without using magnetic adsorbent.
\end{abstract}


Thus, the suggested approach was found to be cost-effective and environmentally friendly for sewage treatment.

Keywords: Magnetism, optimization, sewage, steel wool, turbidity

\section{INTRODUCTION}

Various types of effluent can be found from residence facilities, manufacturing, or any administration, as well as environmental surroundings, including from vehicle exhaust, oil emission, and road construction. The accumulated waste enters wastewater systems uncontrollably (Oliveira et al., 2007). In fact, the increase in water problems promotes economic constriction, decreases environmental quality, and interferes with human sustainability (Rajasulochana \& Preethy, 2016). Therefore, there is an urgent need for a sustainable method that produces an efficient outcome and requires lower operating cost in order to reduce the rapid formation of polluted water. Commonly, the first step in wastewater treatment is the screening of coarse particles from raw sewage through settling (Kwon et al., 2014).

According to Zaidi et al. (2014), numerous conventional methods regarding wastewater treatment have been developed; however, most of them have limitations and drawbacks. For example, filtration requires higher energy consumption and expensive membrane filters, which have a short lifespan and inconvenient to use in a longer period of time (Gupta \& Suhas, 2009). Meanwhile, chemical treatment usually uses a combination of flocculation agents in wastewater treatment. However, this treatment needs higher cost of chemicals, which leads to excess sludge formation as a by-product (Lee et al., 2006). In addition, this treatment highly depends on the $\mathrm{pH}$ level, which is quite challenging to maintain for treating raw wastewater (Kace \& Linford, 1975). Recently, the separation by magnetic force has gained attention due to its capability to remove particles efficiently, cost-efficient technology, and adequate to treat a high volume of wastewater within a short time (Zhou et al., 2009; Wang et al., 2012).

The introduction of high-gradient magnetic separation (HGMS) for wastewater treatment becomes a popular method as the process involves a simple yet effective operation to eliminate unwanted particles from wastewater. During the separation that occurs in a field or a medium, the phenomenon that occurs due to different magnitude of diversification from magnetic flux density is called high gradient (Baik et al., 2010; Baik et al., 2013). In general, HGMS method is an efficient wastewater treatment process due to its capability to reduce various colloidal and suspended matter from the samples by handling weak magnetic particles involved during separation (Hournkumnuard \& Chantrapornchai, 2011; Zheng et al., 2015). The method has been used in various treatment processes, such as 
pharmaceutical research (Ueda et al., 2009; He et al., 2014), biotechnology application (Setchell, 1985; Hoffmann et al., 2002), water and wastewater (Karapinar, 2003; Tomska \& Wolny, 2008; Hwang \& Han, 2015), dye removal (Chen et al., 2011; Narian et al., 2015; Muntean et al., 2018), biological enhancement process (Bitton et al., 1975; Sirisha et al., 2017), and reduction of extracellular protein (Franzreb et al., 2006; Käppler et al., 2009).

One of the unique characteristics of HGMS compared to other separation methods is the selectivity mechanism that uses magnetic force to execute particle's capture movement. This is due to the different level of susceptibility between particles and magnetic field in the sample (Takayasu et al., 1984; Blamire et al., 2009; Ambashta \& Sillanpää, 2010). Therefore, an additional method to increase the magnetic gradient other than using higher magnet strength is by adding steel wool. As claimed by Dhoble et al. (2011), greater magnetization generated by magnet strength and higher magnetic gradient through the presence of steel wool can increase the maximum removal performance of the sample. In achieving productive separation, the presence of steel wool combined with high magnetic strength is significantly important to achieve a successful HGMS application. Fibrous steel wool has a large surface area, which homogenizes with a uniform magnetic field that promotes a higher magnetic gradient (Zheng et al., 2019). Hence, weak magnetic particles are easily attracted to higher magnetic force and simultaneously trapped in the steel wool (Ebner et al., 1997; Mariani et al., 2010). It is proven by Podoynitsyn et al. (2016) who stated that the efficiency of HGMS approach depended on the level of magnetic susceptibility value on particles.

Another factor that promotes higher removal efficiency is the duration of particles exposed to a magnetic field. According to Busch and Busch (1997), the repetitive action of exposing particles to a magnetic field indicates a visible change in particle size. This phenomenon was observed by Rao and Sahu (2013) who insisted that a longer time span of particles exposed to a magnetic field could lead to the accumulation of ionic charges approaching pollutant charges in a sample. It was also convinced by Oshitani et al. (1999), that the presence of ionic charges during conformational changes of water molecules was significantly essential for removal efficiency. In addition, the magnetic effect is likely influenced by the area that consists of higher charge density (e.g., steel wool) in order to produce a competent result or output. Thus, a combination with the frequency of exposure to a magnetic field is necessary to increase the efficiency of wastewater treatment (Baker et al., 1997).

During previous study, application of response surface methodology (RSM) was widely used in optimizing the unwanted materials removal performance on water and wastewater treatment by adding magnetic particles or magnetic seeding. For example, zeolite magnetic nanocomposite was acknowledged as excellent adsorbent reacted to excessive amount of arsenic that majorly affected to the environment (Gugushe et al., 
2019). RSM analysis was conducted to determine the most optimum efficient variables to achieve higher arsenic removal performance. Captivating by the capability of magnetic adsorbent, Liu et al. (2016) modelled a novel magnetic ion imprinted polymer to optimize an optimum treatment of strontium (II) ions (Sr(II)) on wastewater via RSM. Similarly, a magnetic adsorbent known as clinoptilolite (CPL) used for lead removal on wastewater and RSM analysis was utilized to optimize $\mathrm{pH}$, temperature, lead concentration as well as dosage adsorbent in order to excel the removal performance (Javanbakht \& Ghoreishi, 2017). Additionally, Hwang and Han (2015) revealed that by applying $14.1 \mathrm{~min}$ of mixing time with $22.1 \mathrm{mgL}^{-1}$ amount of magnetic iron oxide nanoparticles, produced $90.8 \%$ of reduction in sludge water content. It is much better than conventional method that takes longer time and depends only by gravity alone.

However, most of previous researches only limited to application of magnetic seeding in order to treat unwanted particles on water and wastewater treatment. Additionally, some of few drawbacks were encountered using magnetic seeding as such complex substances, highly in cost production as well as unable to recover completely if it flowed away by river. Hence, in this study, it would be an interest to expand the significant of high gradient performance only by combination between magnet strength and non-corrosive stainless steel wool. In the present study, the removal of suspended matter was investigated through turbidity test. Therefore, the main focus is given to increase magnetic gradient which is expected to boost turbidity removal by including non-corrosive stainless steel wool as a contribution factor together with a permanent magnet without using any magnetic adsorbent.

The magnet strength, circulation time, and steel wool were selected as the critical independent values and turbidity removal as the response, which were optimized using central composite design (CCD) under response surface methodology (RSM). CCD method was selected due to efficiency on experimental data information based on variable conditions effects. It was expected that from the sufficient number of runs in experimental design, hence, it provides a precise prediction as well as better performance for quadratic equation model (Asghar et al., 2014). A predicted model was generated using design of experiment to determine the optimum variable conditions. A statistical mathematical equation was developed in order to enhance turbidity removal for further study in the future.

\section{MATERIALS AND METHODS}

\section{Material for Preparing of Operating Design}

Initially, fresh samples were collected at Pulai Emas Indah Water Konsortium (IWK) every week. A magnetic reactor was built and fabricated at Universiti Teknologi Malaysia (UTM) with five slots for allocating permanent magnets. Polyvinyl chloride (PVC) pipe was used because of the pipe material is not influenced by a permanent magnet; thus, the particles 
are exposed directly into the magnetic field without external disturbance. A permanent magnet was made from neodymium-iron-boron $(\mathrm{NdFeB})$ composition and manufactured by Ningbo Newland International Trade Co. Ltd. China. Each permanent magnet has a square shape with two faces of $100 \mathrm{~mm} \times 50 \mathrm{~mm}$, including $5 \mathrm{~mm}$ of thickness.

All five sets of permanent magnets were allocated at an inverted position (i.e., different poles of the magnet faced each other) operating magnetic design. Three variables were used in the experiment, namely the amount of steel wool, magnet strength, and circulation time at a constant flow rate of $1 \mathrm{ml} / \mathrm{s}$. The steel wool used in the experiment was classified as noncorrosive stainless steel with the diameter of $60 \mu-80 \mu$. The steel wool was manufactured by Lih Feng Jiing Enterprise Co. Ltd. Taiwan. Installing non-corrosive stainless steel wool into the PVC pipe produces a mechanism to increase the gradient of magnetic separation in operating design. The operating magnetic design is shown in Figure 1.

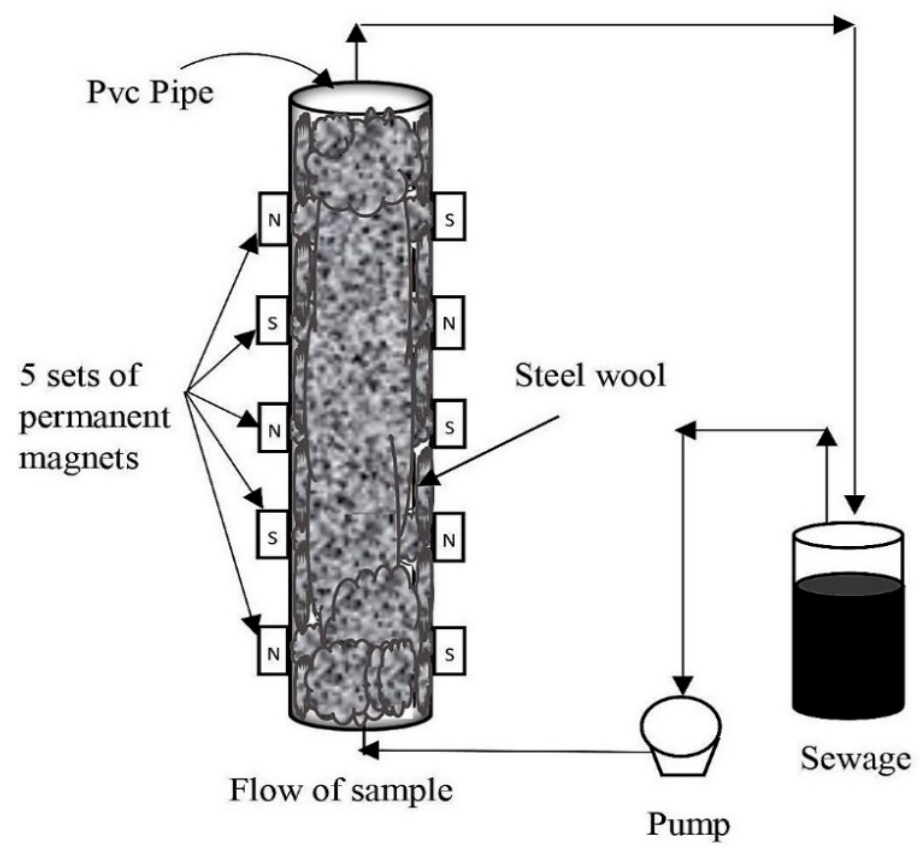

Figure 1. Design of experiment for operating high-gradient magnetic separation

\section{Experimental Setup}

The experiment was conducted with three different proportions of steel wool (40 g, $80 \mathrm{~g}$, and $120 \mathrm{~g})$ and magnet strength $(140 \mathrm{mT}, 195 \mathrm{mT}$, and $250 \mathrm{mT})$ under several time intervals of $24 \mathrm{~h}$ circulation time. Non-corrosive stainless steel wool was replaced each time after running a test. Therefore, no potential corrosion could occur during the circulation of the sample. During a certain interval time, a sample of $20 \mathrm{ml}$ was taken from a plastic bottle to 
conduct turbidity test. Turbidity test was measured by using Mi415 Turbidimeter following the Standard Method No. 2130 (APHA, 2005). The pH was measured using ORION 2 $\mathrm{pH}$ meter. $\mathrm{pH}$ reading and turbidity values throughout the experiment were observed at 7.0-7.2 and 19-125 NTU, respectively. The experiments were repeated twice to ensure a better estimation of the results and avoid bias. Initially, fresh sewage with no treatment was utilized as a control variable and compared with the treated samples.

\section{Design of Experiment}

The statistical prediction of design of experiment for turbidity test was carried out by using Design Expert 8.0.7 software. In this study, central composite design (CCD) under response surface methodology (RSM) was executed in order to optimize the optimum operating magnetic design. Three critical independent variables were selected, namely magnet strength (A), circulation time (B), and steel wool (C) for observing the turbidity removal performance as the response $\left(\mathrm{Y}_{1}\right)$. The range of each independent variable is presented in Table 1.

Table 1

The range of values of independent variables

\begin{tabular}{llllll}
\hline Variables & Coding & Units & \multicolumn{3}{c}{ Level of range } \\
\cline { 4 - 6 } & & & -1 & 0 & +1 \\
\hline $\begin{array}{l}\text { Magnet } \\
\text { strength }\end{array}$ & $\mathrm{A}$ & $\mathrm{mT}$ & 140 & 195 & 250 \\
$\begin{array}{l}\text { Circulation } \\
\text { time }\end{array}$ & $\mathrm{B}$ & $\mathrm{h}$ & 1 & 12.5 & 24 \\
Steel wool & $\mathrm{C}$ & $\mathrm{g}$ & 40 & 80 & 120 \\
\hline
\end{tabular}

By applying CCD, the number of run $(\mathrm{N})$ in Equation 1 obtained by $2^{n}$, which represents the factorial runs, $2 n$ as the axial runs with the complementary of $n_{c}$ as the center of runs, and $n$ as the factors of experimental design (Behera et al., 2018). Three-level three-factors CCD was utilized to produce a second-order polynomial model that consists of 20 runs of experiments, including eight factorial points, six axial points, and six center points in this study.

$$
N=2^{n}+2 n+n_{c}=2^{3}+(2 \times 3)+6=20
$$

\section{Statistical Analysis}

A predicted design matrix was produced by $\mathrm{CCD}$ for conducting experiments in a sequence. 
Then, complete experimental data were further analyzed using RSM, which generated the optimum operating magnetic design equation for turbidity removal, as well as surface and contour plots. A general mathematical equation can be obtained by determining the correlation between the optimal critical independent values and the response as expressed in Equation 2:

$$
Y=\beta_{0}+\sum_{i=1}^{n} \beta_{i} X_{i}+\sum_{i=1}^{n} \beta_{i i} X_{i}^{2}+\sum_{i=1}^{n} \sum_{j=i+1}^{n} \beta_{i j} X_{i} X_{j}+\varepsilon
$$

where $\mathrm{Y}$ is defined as the output of experiment; $\beta_{0}$ is a constant regression coefficient; $\beta_{i}$ represents a linear coefficient; $\beta_{i i}$ portrays quadratic effect; $\beta_{i i}$ represents the relation of coefficient; $n$ is the number of factors involved in the study; $X_{i} X_{j}$ is the coded value of critical independent values, and $\varepsilon$ is the random error detected as the nuisance between the predicted and actual values in the design. There are two ways of predicting the well-fitted quality design in order to evaluate the capability of experimental design optimization: the coefficient of determination $\left(\mathrm{R}^{2}\right)$ and the analysis of variance (ANOVA) (Lee et al., 2011; Liu et al., 2016; Su et al., 2016).

The accuracy of the model based on $\mathrm{R}^{2}$ coefficient analysis was validated and determined whether the model was accepted or rejected based on the probability value known as the $p$-value at a confidence level of $95 \%$. Meanwhile, the ANOVA table was evaluated by Fisher's test, or also known as the $F$-test. Additionally, the quadratic effect from regression analysis in the ANOVA table displayed response and contour plot data by alternately using two critical independent values while keeping another critical independent value at constant in order to yield an optimum response.

\section{RESULT AND DISCUSSION}

\section{Development of Model}

By using Design Expert 8.0.7 software, the recommended output model was a quadratic model. A mathematical equation for optimizing turbidity removal through operational design was developed both in actual and coded factors, as shown in Table 2. Every positive sign in the mathematical equation is known as the synergistic effect where a negative sign indicates the antagonistic effect (Shuit et al., 2010; Lee et al., 2011).

The turbidity removal performance is presented in Table 3. In total, 20 experimental runs were performed according to CCD in actual values. The observed turbidity performance varied between $27 \%$ and $93 \%$ removal.

The highest removal of $93 \%$ was achieved when all the critical independent variables were at the highest values, including magnet strength of $250 \mathrm{mT}$, the proportion of noncorrosive stainless steel wool of $120 \mathrm{~g}$, and running the experiment for $24 \mathrm{~h}$ of circulation 
Table 2

An empirical model for turbidity removal both in coded and actual factors

\begin{tabular}{lll}
\hline $\begin{array}{l}\text { Response/ } \\
\text { Output }\end{array}$ & Coded factors & Actual factors \\
\hline Turbidity $\left(\mathrm{Y}_{1}\right)$ & $+73.56+7.60 A+11.60 B$ & $-43.4201+0.4469 A+$ \\
& $+15.70 C+2.13 A B-$ & $2.5131 B+0.5558 C+$ \\
& $2.87 A C+4.88 B C-1.91 A^{2}$ & $0.0336 \times e^{-3} A B-$ \\
& $-15.91 B^{2}-0.41 C^{2}$ & $0.0131 \times e^{-3} A C+$ \\
& $0.0106 B C-0.0631 \times$ \\
& $e^{-4} A^{2}-0.1203 B^{2}-$ \\
& $0.0256 \times e^{-4} C^{2}$ \\
&
\end{tabular}

Notes. A: magnet strength; B: circulation time; C: steel wool; $\mathrm{Y}_{1}$ : turbidity removal

Table 3

A complete matrix design of experiment in actual values

\begin{tabular}{lllll}
\hline Run no & A $(\mathrm{mT})$ & B (hour) & C (gram) & $\mathrm{Y}_{1}(\%)$ \\
\hline 1 & 140 & 24 & 120 & 83 \\
2 & 195 & 12.5 & 80 & 73 \\
3 & 195 & 12.5 & 80 & 72 \\
4 & 140 & 1 & 120 & 50 \\
5 & 1 & 80 & 44 \\
6 & 195 & 24 & 40 & 62 \\
7 & 250 & 1 & 40 & 27 \\
8 & 140 & 12.5 & 80 & 77 \\
9 & 195 & 24 & 80 & 67 \\
10 & 195 & 12.5 & 80 & 76 \\
11 & 250 & 12.5 & 120 & 87 \\
12 & 195 & 24 & 40 & 32 \\
13 & 140 & 12.5 & 80 & 79 \\
14 & 195 & 12.5 & 40 & 55 \\
15 & 195 & 1 & 40 & 40 \\
16 & 250 & 1 & 120 & 60 \\
17 & 250 & 24 & 120 & 93 \\
18 & 250 & 12.5 & 80 & 71 \\
19 & 195 & 12.5 & 80 & 78 \\
20 & 195 & 12.5 & 80 & 63 \\
\hline
\end{tabular}


time. Meanwhile, the lowest removal of $27 \%$ was recorded for the magnet strength of 140 $\mathrm{mT}, 40 \mathrm{~g}$ of non-corrosive stainless steel wool, and the turbidity test was conducted during the first hour of circulation time. The ANOVA table is shown in Table 4. From the Table 4, the experimental data model was declared as significant according to the $F$-value of 49.15 and $p$-value $<0.0001$, which simultaneously stated that the model is statistically significant as the $p$-value is less than 0.05 or significant at $95 \%$ of confidence level.

Table 4

Adequacy of turbidity removal through ANOVA table

\begin{tabular}{|c|c|c|c|c|c|c|c|}
\hline Response & Source & $\begin{array}{l}\text { Sum of } \\
\text { square }\end{array}$ & $\begin{array}{l}\text { Degree of } \\
\text { freedom }\end{array}$ & $\begin{array}{l}\text { Mean } \\
\text { square }\end{array}$ & $\begin{array}{l}\mathrm{F} \\
\text { value }\end{array}$ & Prob $>F$ & Remarks \\
\hline \multirow[t]{15}{*}{$\mathrm{Y}_{1}$} & Model & 6191.00 & 9 & 687.89 & 49.15 & $<0.0001$ & significant \\
\hline & A & 577.60 & 1 & 577.60 & 41.27 & $<0.0001$ & \\
\hline & B & 1345.60 & 1 & 1345.60 & 96.15 & $<0.0001$ & \\
\hline & $\mathrm{C}$ & 2464.90 & 1 & 2464.90 & 176.12 & $<0.0001$ & \\
\hline & $\mathrm{AC}$ & 66.12 & 1 & 66.12 & 4.72 & 0.0548 & \\
\hline & $\mathrm{BC}$ & 190.13 & 1 & 190.13 & 13.58 & 0.0042 & \\
\hline & $\mathrm{B}^{2}$ & 696.02 & 1 & 696.02 & 49.73 & $<0.0001$ & \\
\hline & Residual & 139.95 & 10 & 14.00 & & & \\
\hline & $\begin{array}{l}\text { Lack of } \\
\text { Fit }\end{array}$ & 81.95 & 5 & 16.39 & 1.41 & 0.3568 & $\begin{array}{l}\text { not } \\
\text { significant }\end{array}$ \\
\hline & $\begin{array}{l}\text { Pure } \\
\text { Error }\end{array}$ & 58.00 & 5 & 11.60 & & & \\
\hline & $\begin{array}{l}\text { Cor } \\
\text { Total }\end{array}$ & 6330.95 & 19 & & & & \\
\hline & Std. Dev. & 3.74 & R-Squared & 0.9779 & & & \\
\hline & Mean & 64.45 & $\begin{array}{l}\text { Adj } \\
\text { R-Squared }\end{array}$ & 0.9580 & & & \\
\hline & C.V. $\%$ & 5.80 & $\begin{array}{l}\text { Pred } \\
\text { R-Squared }\end{array}$ & 0.8227 & & & \\
\hline & Press & 1122.22 & $\begin{array}{l}\text { Adeq } \\
\text { Precision }\end{array}$ & 26.386 & & & \\
\hline
\end{tabular}

Notes. A: magnet strength; B: circulation time; C: steel wool; $\mathrm{Y}_{1}$ : turbidity removal; Cor Total: Correlation total; Std. Dev: Standard deviation; C.V.: Coefficient of variation; Adj R-Squared: Adjusted R ${ }^{2}$; Pred R-Squared: Predicted R²; Adeq Precision: Adequate precision 
Furthermore, all three critical independent variables were pronounced as statistically significant as the $p$-value was less than 0.05 in the experimental model. However, it was found that non-corrosive stainless steel wool had a major effect on the turbidity removal, with the $F$-value of 176.12 compared to others. Nevertheless, all the independent variables were considered as potentially influential towards the turbidity removal performance in sewage treatment. In addition, at the first-order coefficient effect or linear effect, two combinations of independent variables were statistically significant. The combination between magnet strength and steel wool, as well as the combined effects between circulation time and steel wool were statistically significant with $p$-values of 0.0548 and 0.0042 , respectively. The insignificant variable can be eliminated as it has limited influence, which degrades the optimum performance of a model (Amr et al., 2014).

Furthermore, the evaluation of the well-fitted model could also be observed through several critical values from the ANOVA table. For example, the expected remark of lack-of-fit (LOF) should be not significant with $p$-value $>0.05$, which is fundamental for determining that the model is adequately fitted to the experimental data (Bezerra et al., 2008). It is verified that the possibility of the input between the regressor-response relationships is unnecessary to be included in the model (Noordin et al., 2004). From this study, the lack-of-fit (LOF) was observed as insignificant with the $p$-value of 0.3568 , which was higher than 0.05; thus, the obtained model was statistically significant. Moreover, the $\mathrm{R}^{2}$ value closer to 1 can be suggested as reliable as predicted by the model Su et al. (2016), where $\mathrm{R}^{2}$ was determined as $97.8 \%$. This could explain that the data fitted to the model and promoted an optimum estimation of the output in the range of study.

In statistics, the signal of noise ratio is recognized as adequate if the value of adequate precision coefficient (AP) is higher than four (Markandeya et al., 2017). The AP in this study was 26.386 (i.e., higher than four), and the model could be claimed as desirable. The coefficient of variation (CV) should be less than $10 \%$ in order to achieve an optimum model; in this study, the CV obtained was significantly higher at $5.8 \%$, but the value was still acceptable for a reliable model (Javanbakht \& Ghoreishi, 2017). Apparently, the competency of a model can be evaluated by analyzing the pattern of a normal probability graph of residuals. Residuals are known as the distinct pattern between the predicted and observed response data (Lee et al., 2011). In general, a normal distribution is defined when all the residuals data would align and remain closer to the straight line; however, it is expected that some of the residual's plots would spread during the experiment, as shown in Figure 2(a) (Amr et al., 2014). Nevertheless, as long as the predicted experiment values were included between the tolerance limits represent by the red lines in Figure 2(b), the model could still be indicated as statistically significant (Zaidi et al., 2014).

In addition, all randomness and structureless plots signified that the model is satisfactorily adequate for the experimental data, and there is no need for the assumption 


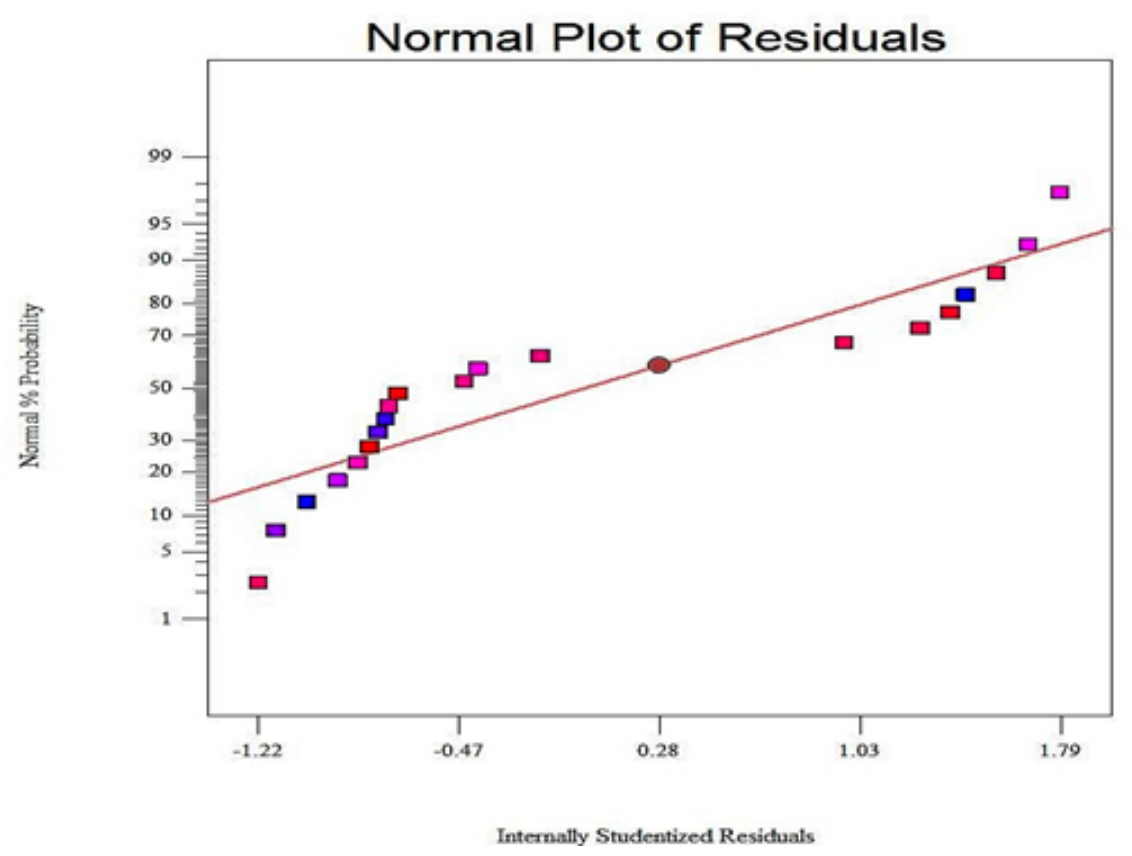

(a)

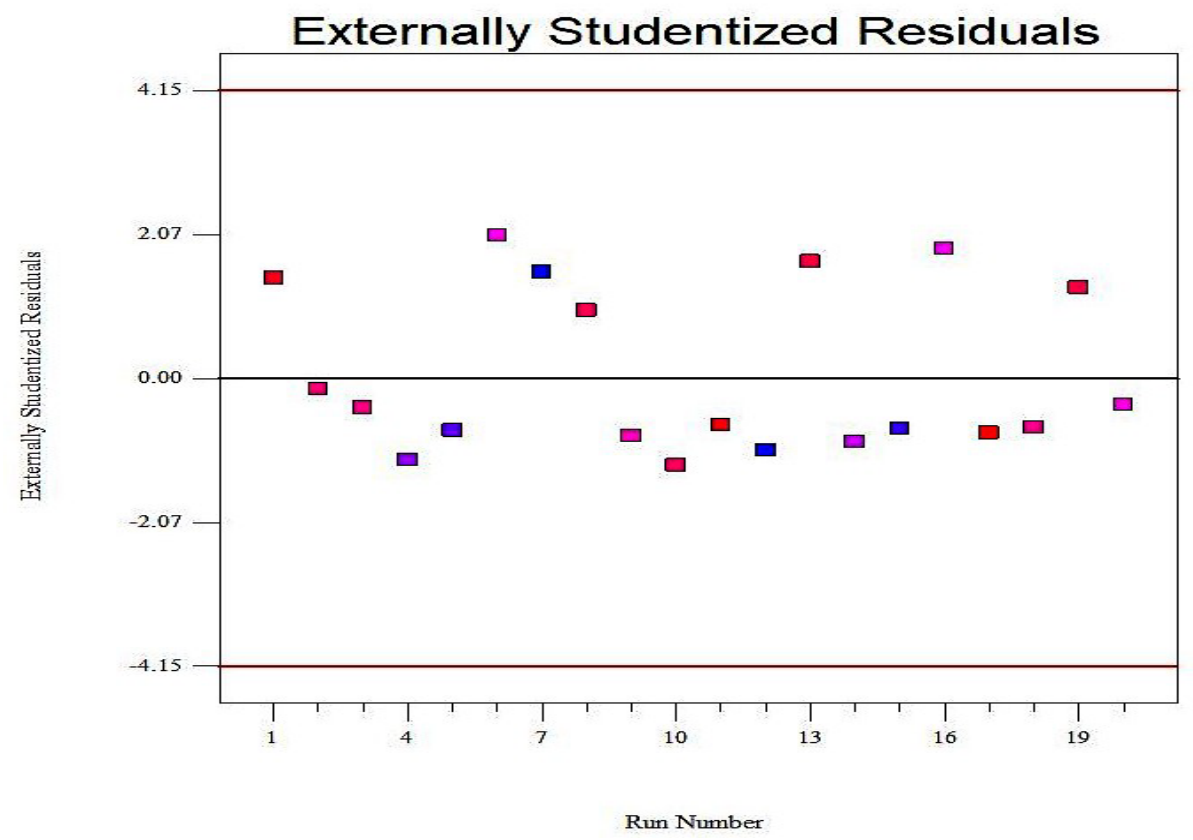

(b)

Figure 2. Turbidity removal for (a) normal probability plot with residuals and (b) predicted experiment data with residual plot 
of variance that could promote the transformation of output variables (Noordin et al., 2004; Behera et al., 2018). Consequently, all the essential characteristics for determining the significance of the model are well accomplished by the experimental data; thus, the design model can be used for further studies by evaluating surface and contour plots.

\section{The Combined Effect of Magnet Strength and Steel Wool towards Turbidity}

In this section, RSM was used to evaluate the relationship for the combined correlation effects of three-level factors on turbidity removal. Figure 3 represents the relationship between the significant interaction of magnet strength (A) and steel wool (C) through (a) a surface plot and (b) a contour plot. The values on both graphs are actual values. Turbidity removal displayed combined effects of $A$ and $C$ at the circulation time of $12.5 \mathrm{~h}$, as shown in Figure 3 below. From the 3D surface plot in Figure 3(a), turbidity removal increased significantly due to the influence of increasing magnet strength (140 mT to $250 \mathrm{mT})$ and by adding $40 \mathrm{~g}$ to $120 \mathrm{~g}$ of non-corrosive stainless steel wool at constant circulation time (12.5 h). The maximum turbidity removal observed was $91.6 \%$. On the contrary, both of the lowest values of steel wool and magnet strength did not accelerate turbidity removal. This could be explained by Ebner et al. (1997) and Li et al. (2012), who stated that when the high-gradient magnetic field engaged with non-corrosive stainless steel wool, the gradient of the magnetic field increased appropriately as steel wool started to magnetize.

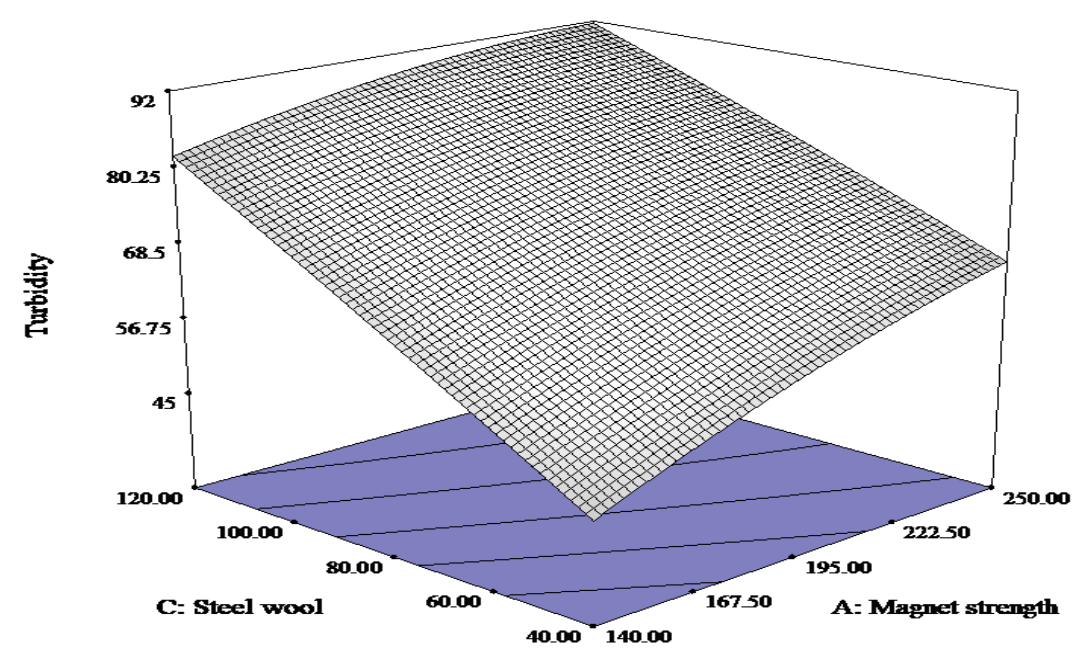

(a)

Figure 3. Relationship between magnet strength (A) and steel wool (C) on turbidity removal at circulation time of $12.5 \mathrm{~h}$ through (a) surface plot and (b) contour plot 


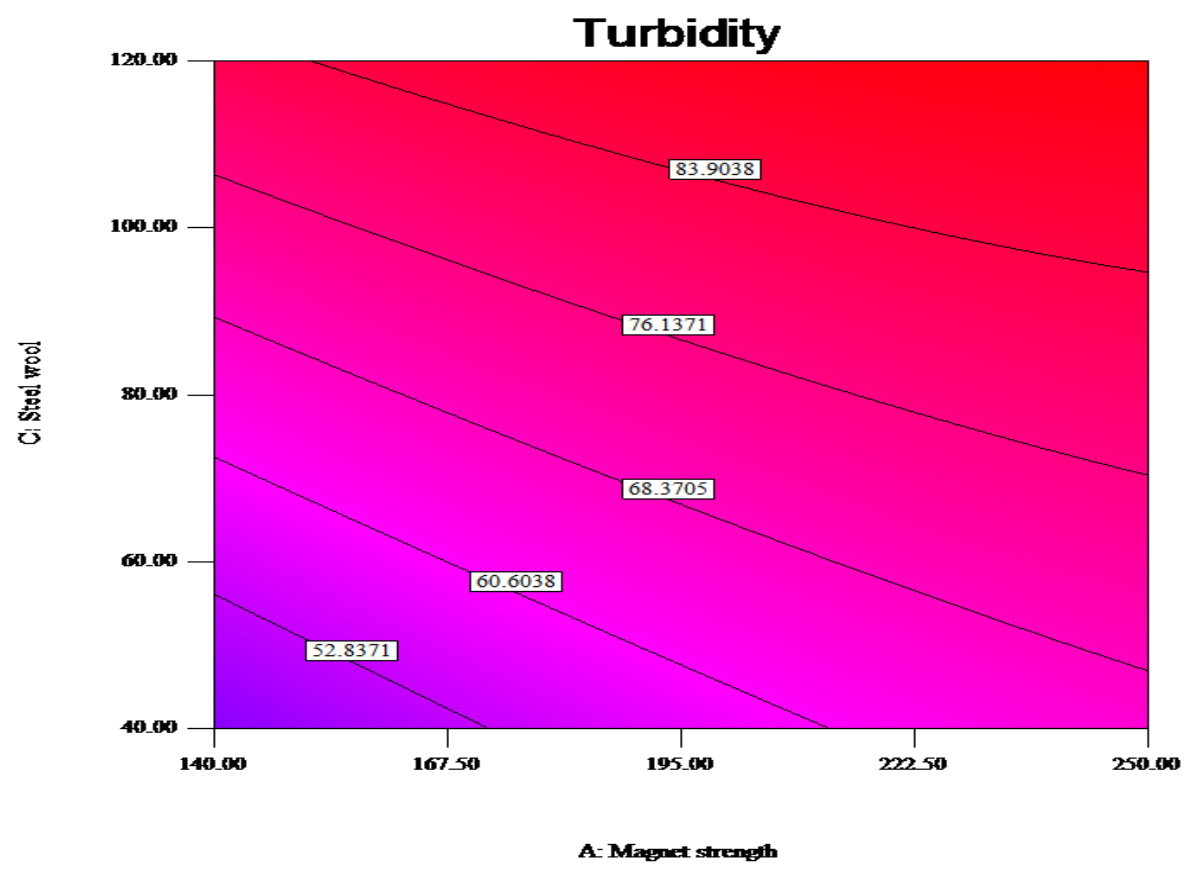

(b)

Figure 3.(Continued)

It was also claimed by Rao and Sahu (2013), that when magnet strength was increased to increase magnetic gradient, charged ions were produced, which attracted to different charges from water molecules in a sample. Thus, weak magnetized particles and tiny pollutant in sewage could be removed easily. The presence of non-corrosive stainless steel wool itself provides higher density or compression in a magnetic field medium (Hatch \& Stelter, 2001; Ge et al., 2017; Ren et al., 2017). Whenever a particle circulates through a pipe, there is a higher chance of the particle being potentially exposed and magnetized, which is a significantly important process in HGMS. When a particle is magnetized, it is simultaneously attracted to magnetized steel wool; thus, higher turbidity removal can be achieved.

As proven from the contour plot in Figure 3(b), more than 50\% of turbidity removal was observed in the early experiment, followed by a sharp increase of turbidity removal as the magnet strength and steel wool increased proportionately. Hence, the correlation between magnet strength and non-corrosive stainless steel wool is the most important relationship for turbidity removal in sewage treatment. 


\section{The Combined Effect of Circulation Time and Steel Wool towards Turbidity}

Figure 4 illustrates the relationship of circulation time (B) and steel wool (C) through (a) a surface plot and (b) a contour plot. Turbidity removal displayed the combined effects of B and C at magnet strength of $195 \mathrm{mT}$ in Figure 4 (a). At a constant value of magnet strength, the $3 \mathrm{D}$ surface plot showed that the increase of circulation time explained the significant increase on turbidity removal (45\% to $74 \%$ ) at low and intermediate levels of steel wool. According to Figure 4 (b), the shape of the contour revealed that more than $75 \%$ of turbidity removal was achieved for steel wool and circulation time at intermediate and high levels. From this circumstance, it could be analyzed that the longer circulation time involved, the higher turbidity removal could be obtained.

This correlation is obtained when magnetized particles circulate repeatedly and continuously through a magnetic field, and the particles are able to retain magnetic memory. Magnetic memory is essential for particles as it affects magnetization behavior; thus, particles start to accumulate and attract particles with different charges (Baker \& Judd, 1996; Colic \& Morse, 1999). According to Higashitani et al. (1992), magnetic memory can be preserved by particles until 143 hours after being exposed to a magnetic field for 30 min. Meanwhile, Sohaili (2003) stated that particles could retain the magnetic memory almost permanently if they were continuously exposed in a longer period of time. Therefore, bigger particles are formed and could be easily trapped in fibrous steel wool. The increment of turbidity removal still occurred when non-corrosive stainless steel wool was added until $120 \mathrm{~g}$ and circulation time about to reach $24 \mathrm{~h}$.

However, the turbidity removal reached a plateau when both independent variables reached the maximum values. This could be further explained that particles from the sample are almost fully acquired in fibrous non-corrosive stainless steel wool; thus, a treated sample with less colloidal and residual suspended matter can be achieved. Similarly, a previous study on chemical oxygen demand (COD) reduction using electromagnetic by Rao and Sahu (2013) found that a longer duration of exposure time to a magnetic field promoted a higher chance for each particle to achieve ionic charge. Therefore, charged particles potentially have a greater tendency to attract either positively or negatively charged particles and simultaneously form bigger particles that would be either trapped in the steel wool or settled down by gravity.

\section{Optimization of Model}

The optimization of the model was conducted using Design Expert 8.0.7 software. This software can statistically correlate each variable within the values in order to optimize the most optimum operating magnet design for this study, thus producing a desirable response. Each of the critical operational variable (i.e., A, B, and C) was selected within the range 


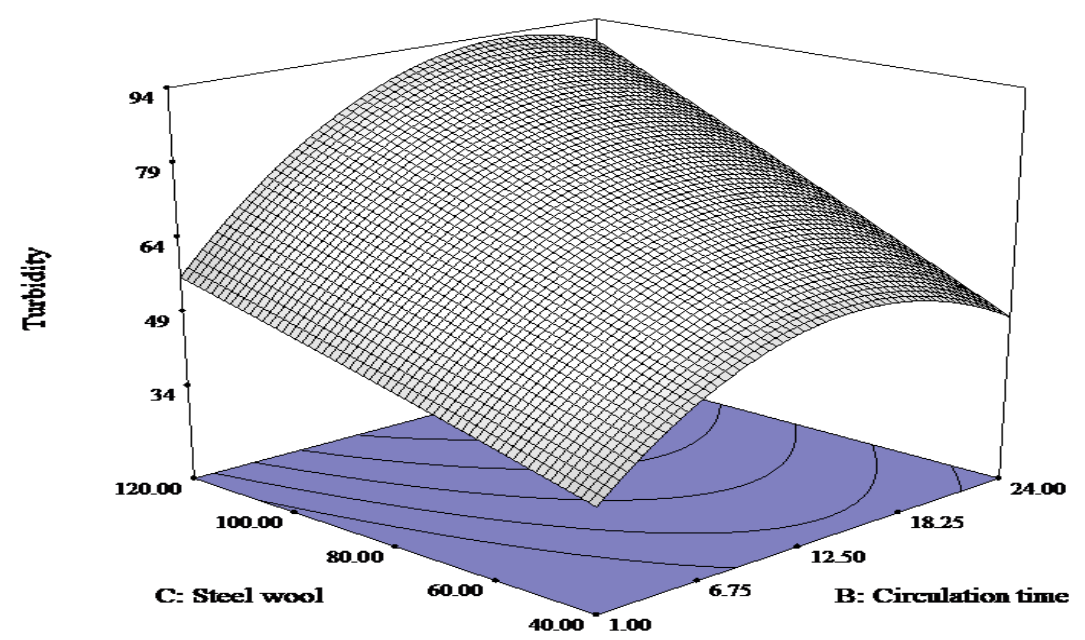

(a)

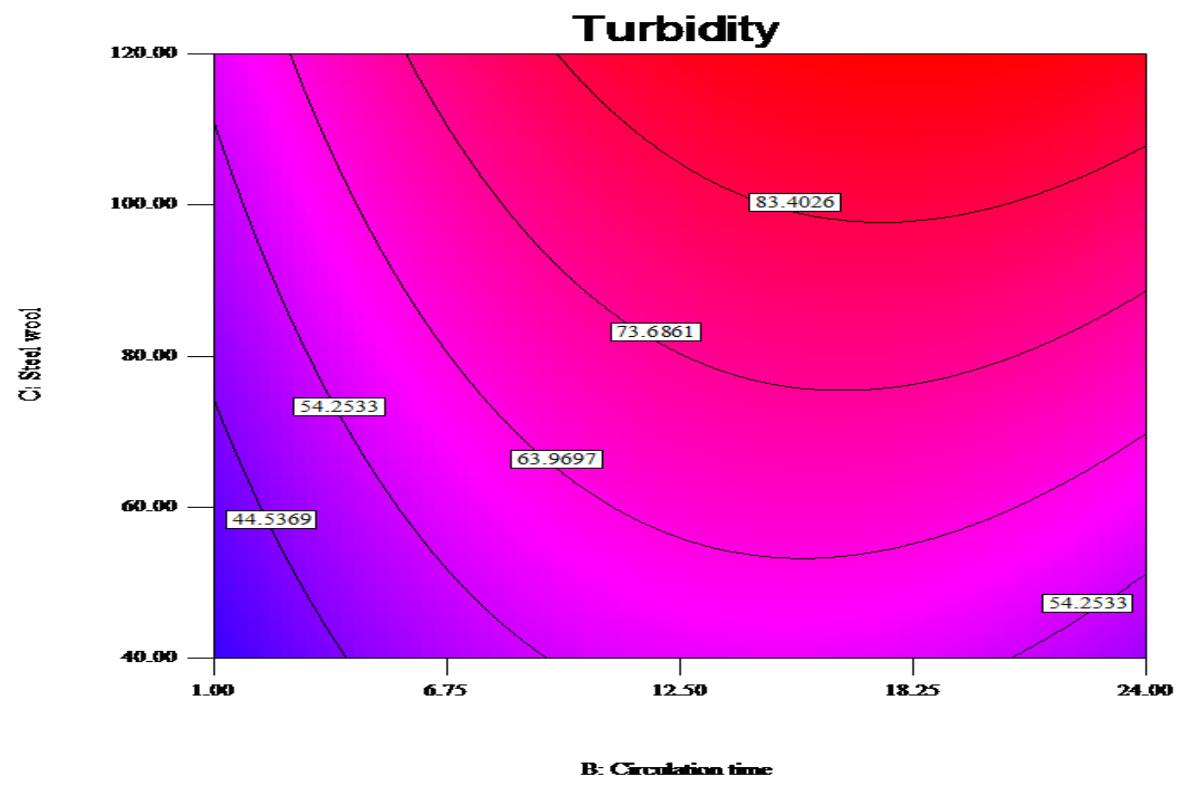

(b)

Figure 4. Relationship between circulation time (B) and steel wool (C) on turbidity removal at magnet strength of $195 \mathrm{mT}$ through (a) surface plot and (b) contour plot 
of values. The output for turbidity removal $\left(\mathrm{Y}_{1}\right)$ was determined as the maximum removal performance according to the selected critical operational variables.

From the optimization, the optimum conditions of A of $245 \mathrm{mT}, \mathrm{B}$ of $16 \mathrm{~h}$, and $\mathrm{C}$ of $116 \mathrm{~g}$ are expected to approximately achieve $94 \%$ of turbidity removal. In order to ensure that the validation of optimization process correlates significantly with experimental design, an additional experiment was conducted to analyze the optimum operational conditions for avoiding any bias result (Lee et al., 2011; Hwang \& Han, 2015; Su et al., 2016). By using the same optimum operational conditions, turbidity removal of $90.3 \%$ was achieved with difference only $3.7 \%$ of error compared to predicted response value. Based on the small difference between the predicted response value and the experiment value, it can be concluded that the difference is still within the maximum range of response (Lee et al., 2011; Behera et al., 2018). Therefore, the predicted optimization model was valid for further study references. Moreover, the normal probability analysis graph acknowledged that the error distribution from experimental data was adequately distributed along the line which interprets the design model adjusted well with experimental data (Peng et al., 2020). Additionally, according to the ANOVA table analysis, the error between the $\mathrm{R}^{2}$ value (i.e. 0.9779) and the adjusted $\mathrm{R}^{2}$ value (i.e. 0.9580 ) was 0.02 which less than 0.2 , verified that accuracy of experimental design ( $\mathrm{Su}$ et al., 2016). Most prominently, $\mathrm{R}^{2}$ value of actual data was higher than $\mathrm{R}^{2}$ value of predicted data (i.e. 0.8227) which indicated that the experimental data suited well with design of experiment. Hence, it certified that the magnetic strength, circulation time and non-corrosive stainless steel wool had effects of $97.8 \%$ on the suspended matter removal by turbidity test. Therefore, all of optimum operating magnetic design values were showed that an acceptable predictability and precisely accuracy for determining suspended matter removal performance.

\section{CONCLUSIONS}

Combination of three different amounts of non-corrosive stainless steel wool and magnetic strengths were employed to maximize the removal of suspended matter under several time intervals of $24 \mathrm{~h}$ circulation time. As a conclusion, the maximal of turbidity removal was indeed increased by magnetic gradient as it occurred when higher amount of non-corrosive stainless steel wool combined with higher magnetic strength. Therefore, without using any additional magnetic adsorbent, suspended matter removal could be enhanced by using optimum magnetic gradient. According to the ANOVA analysis, all of three operating magnetic design conditions affected the suspended matter removal statistically significant as the $p$-value is less than 0.05 . The extend of suspended matter removal was escalated at optimized operating magnetic design to obtain highest removal percentage by turbidity test. The experimental output was determined as $90.3 \%$ using the optimized conditions of magnet strength (A) of $245 \mathrm{mT}$, circulation time (B) of $16 \mathrm{~h}$, and steel wool (C) of 116 
grams. The empirical model stipulated that the suspended matter removal by turbidity, which subsequently improved water quality.

\section{ACKNOWLEDGEMENT}

A very special thank to both Universiti Teknologi Malaysia (UTM) and Ministry of Science, Technology and Innovation (MOSTI) for supporting this research titled " Optimization and Modelling of Turbidity Removal of Sewage using High Gradient Magnetic Separation (HGMS) by Response Surface Methodology (RSM)" financially (Project No. 4S032).

\section{REFERENCES}

Ambashta, R. D., \& Sillanpää, M. (2010). Water purification using magnetic assistance: A review. Journal of Hazardous Materials, 180, 38-49.

APHA. (2005). Standard methods for the examination of water and wastewater (21st Ed.). Washington DC, USA: American Public Health Association.

Amr, S. S. A., Aziz, H. A., \& Bashir, M. J. K. (2014). Application of response surface methodology ( RSM ) for optimization of semi-aerobic landfill leachate treatment using ozone. Applied Water Science, 4, 1-10.

Asghar, A., Raman, A. A. A., \& Daud, W. M. A. W. (2014). A comparison of central composite design and taguchi method for optimizing fenton process. The Scientific World Journal, 2014, 1-14.

Baik, S. K., Ha, D. W., Ko, R. K., \& Kwon, J. M. (2010). Magnetic field and gradient analysis around matrix for HGMS. Physica C, 470, 1831-1836.

Baik, S. K., Ha, D. W., Kwon, J. M., Lee, Y. J., \& Ko, R. K. (2013). Magnetic force on a magnetic particle within a high gradient magnetic separator. Physica C: Superconductivity, 484, 333-337.

Baker, J. S., \& Judd, S. J. (1996). Magnetic amelioration of scale formation. Water Research, 30(2), 247-260.

Baker, J. S., Judd, S. J., \& Parsons, S. A. (1997). Antiscale magnetic pretreatment of reverse osmosis feedwater. Desalination, 110, 151-165.

Behera, K. S., Meena, H., Chakraborty, S., \& Meikap, B. C. (2018). Application of response surface methodology (RSM) for optimization of leaching parameters for ash reduction from low-grade coal. International Journal of Mining Science and Technology, 28(4), 621-629.

Bezerra, M. A., Santelli, R. E., Oliveiraa, E. P., Villara, L. S., \& Escaleira, L. A. (2008). Response surface methodology (RSM) as a tool for optimization in analytical chemistry. Talanta, 76, 965-977.

Bitton, G., Fox, J. L., \& Strickland, H. G. (1975). Removal of algae from Florida lakes by magnetic filtration. Journal of Applied Microbiology, 30(6), 905-908.

Blamire, M. G., Dinner, R. B., Wimbush, S. C., \& MacManus-Driscoll, J. L. (2009). Critical current enhancement by Lorentz force reduction in superconductor - ferromagnet nanocomposites. Superconductor Science and Technology, 22, 1-6. 
Busch, K. W., \& Busch, M. A. (1997). Laboratory studies on magnetic water treatment and their relationship to a possible mechanism for scale reduction. Desalination, 109, 131-148.

Chen, W., Lin, H., \& Zhang, S. (2011). Study on treatment of printing and dyeing wastewater by magnetic seed coagulation - high gradient magnetic separation. Applied Mechanics and Material, 71-78, 2689-2694.

Colic, M., \& Morse, D. (1999). The elusive mechanism of the magnetic memory of water. Colloids and Surfaces A: Physicochemical and Engineering Aspects, 154, 167-174.

Dhoble, R. M., Lunge, S., Bhole, A. G., \& Rayalu, S. (2011). Magnetic binary oxide particles (MBOP): A promising adsorbent for removal of As(III) in water. Water Research, 45(16), 4769-4781.

Ebner, A., D., Ritter, J., A., \& Ploehn, H., J. (1997). Feasibility and limitations of nano-level high gradient magnetic separation. Separation and Purification Technology, 11, 199-210.

Franzreb, M., Siemann-Herzberg, M., Hobley, T. J., \& Thomas, O. R. T. (2006). Protein purification using magnetic adsorbent particles. Applied Microbiology and Biotechnology, 70, 505-516.

Ge, W., Encinas, A., Araujo, E., \& Song, S. (2017). Magnetic matrices used in high gradient magnetic separation (HGMS): A review. Results in Physics, 7, 4278-4286.

Gugushe, A. S., Nqombolo, A., \& Nomngongo, P. N. (2019). Application of response surface methodology and desirability function in the optimization of adsorptive remediation of arsenic from acid mine drainage using magnetic nanocomposite : Equilibrium studies and application to real samples. Molecules, 24, 1-15.

Gupta, V. K., \& Suhas. (2009). Application of low-cost adsorbents for dye removal - A review. Journal of Environmental Management, 90(8), 2313-2342.

Hatch, G. P., \& Stelter, R. E. (2001). Magnetic design considerations for devices and particles used for biological high-gradient magnetic separation (HGMS) systems. Journal of Magnetism and Magnetic Materials, 225(1-2), 262-276.

He, J., Huang, M., Wang, D., Zhang, Z., \& Li, G. (2014). Magnetic separation techniques in sample preparation for biological analysis : A review. Journal of Pharmaceutical and Biomedical Analysis, 101, 84-101.

Higashitani, K. O., Okuhara, K., \& Hatade, S. (1992). Effects of magnetic fields on stability of nonmagnetic ultrafine colloidal particles. Journal of Colloid And Interface Science, 152(I), 125-131.

Hoffmann, C., Franzreb, M., \& Höll, W. H. (2002). A novel high-gradient magnetic separator (HGMS) design for biotech applications. IEEE Transactions on Applied Superconductivity, 12(1), 963-966.

Hournkumnuard, K., \& Chantrapornchai, C. (2011). Parallel simulation of concentration dynamics of nanoparticles in High Gradient Magnetic Separation. Simulation Modelling Practice and Theory, 19(2), 847-871.

Hwang, J., \& Han, D. (2015). Optimization and modeling of reduction of wastewater sludge water content and turbidity removal using magnetic iron oxide nanoparticles (MION). Journal of Environmental Science and Health, 50, 1307-1315.

Javanbakht, V., \& Ghoreishi, S. M. (2017). Application of response surface methodology for optimization of lead removal from an aqueous solution by a novel superparamagnetic nanocomposite. Adsorption Science and Technology, 35(1-2), 241-260. 
Kace, J. S., \& Linford, H. B. (1975). Reduced cost flocculation of a textile dyeing wastewater. Journal of Water Pollution Control Federation, 47, 1971-1977.

Karapinar, N. (2003). Magnetic separation of ferrihydrite from wastewater by magnetic seeding and highgradient magnetic separation. International Journal of Mineral Processing, 71(1-4), 45-54.

Käppler, T., Cerff, M., Ottow, K., Hobley, T., \& Posten, C. (2009). In situ magnetic separation for extracellular protein production. Biotechnology and Bioengineering, 102(2), 535-545.

Kwon, H., Ha, D., \& Kim, Y. (2014). Superconducting magnetic separation of powdered activated carbon from aqueous phase. IEEE Transactions on Applied Superconductivity, 24(3), 3-6.

Lee, H. V., Yunus, R., Juan, J. C., \& Tau, Y. H. (2011). Process optimization design for jatropha-based biodiesel production using response surface methodology. Fuel Processing Technology, 92, 2420-2428.

Lee, J. W., Choi, S. P., Thiruvenkatachari, R., Shim, W. G., \& Moon, H. (2006). Evaluation of the performance of adsorption and coagulation processes for the maximum removal of reactive dyes. Dyes Pigments, 69 , 196-203.

Li, S. Q., Wang, M. F., Zhu, Z. A., Wang, Q., Zhang, X., Song, H. Q., \& Cang, D. Q. (2012). Application of superconducting HGMS technology on turbid wastewater treatment from converter. Separation and Purification Technology, 84, 56-62.

Liu, Y., Liu, F., Ni, L., Meng, M., \& Meng, X. (2016). A modeling study by response surface methodology (RSM) on Sr (II) ion dynamic adsorption optimization using a novel magnetic ion. The Royal Society of Chemistry, 6, 54679-54692.

Mariani, G., Fabbri, M., Negrini, F., \& Ribani, P. L. (2010). High-gradient magnetic separation of pollutant from wastewaters using permanent magnets. Separation and Purification Technology, 72(2), 147-155.

Markandeya, Dhiman, N., Shukla, S. P., \& Kisku, G. C. (2017). Statistical optimization of process parameters for removal of dyes from wastewater on chitosan cenospheres nanocomposite using response surface methodology. Journal of Cleaner Production, 149, 597-606.

Muntean, S. G., Nistor, M. A., Muntean, E., Todea, A. G, R. I., \& Cornelia, P. (2018). Removal of colored organic pollutants from wastewaters by magnetite/carbon nanocomposites: Single and binary systems. Journal of Chemistry, 2018, 1-16.

Narian, E., Arami, M., Bahrami, H., \& Pajootan, E. (2015). Modification of nickel ferrite with cationic surfactant: Dye removal from textile wastewater using magnetic separation. Journal of Environmental Engineering, 141(2), 1-10.

Noordin, M. Y., Venkatesh, V. C., Sharif, S., Elting, S., \& Abdullah, A. (2004). Application of response surface methodology in describing the performance of coated carbide tools when turning AISI 1045 steel. Journal of Materials Processing Technology, 145, 46-58.

Oliveira, F. H., Osugi, M. E., Paschoal, F. M. M., Profeti, D., Olivi, P., \& Zanoni, M. V. B. (2007). Electrochemical oxidation of an acid dye by active chlorine generated using $\mathrm{Ti} / \mathrm{Sn}{ }_{(1-\mathrm{x})} \mathrm{Ir}_{\mathrm{x}} \mathrm{O}_{2}$ electrodes. Journal of Applied Electrochemical, 37, 583-592.

Oshitani, J., Yamada, D., Miyahara, M., \& Higashitani, K. (1999). Magnetic effect on ion-exchange kinetics. Journal of Colloid and Interface Science, 210, 1-7. 
Peng, Y., Khaled, U., Al-Rashed, A. A. A. A., Meer, R., Goodarzi, M., \& Sarafraz, M. M. (2020). Potential application of response surface methodology (RSM) for the prediction and optimization of thermal conductivity of aqueous $\mathrm{CuO}$ (II) nanofluid: A statistical approach and experimental validation. Physica A, 554, 1-8.

Podoynitsyn, S. N., Sorokina, O. N., \& Kovarski, A. L. (2016). High-gradient magnetic separation using ferromagnetic membrane. Journal of Magnetism and Magnetic Materials, 397, 51-56.

Rajasulochana, P., \& Preethy, V. (2016). Comparison on efficiency of various techniques in treatment of waste and sewage water - A comprehensive review. Resource-Efficient Technologies, 2(4), 175-184.

Rao, M. S., \& Sahu, O. (2013). Study of electromagnetic waves on industrial waste water. Physics and Materials Chemistry, 1(2), 34-40.

Ren, Z., Lin, Z., Ye, Z., Xiangyu, Z., \& Dongxing, M. (2017). Effects and mechanization of a high gradient magnetic separation process for particulate and microbe removal from ballast water. International Journal of Environmental and Ecological Engineering, 11(6), 553-558.

Setchell, C. H. (1985). Magnetic separations in biotechnology - A review. Journal of Chemical Technology and Biotechnology, 35(3), 175-182.

Shuit, S. H., Lee, K. T., Kamaruddin, A. H., \& Yusup, S. (2010). Reactive extraction of Jatropha curcas L. seed for production of biodiesel: Process optimization study. Environmental Science and Technology, $44,4361-4367$.

Sirisha, K., Suganya, B., Sivasubramanian, V., Bs, V., Swaminathan, D., Babu, A. C., \& Meyyappan, N. (2017). Studies on the effect of pulsed magnetic field on the productivity of algae grown in dye industry effluent. Journal of Applied Biotechnology and Bioengineering, 3(5), 409-413.

Sohaili, J. (2003). Capability of the magnetic technology to increase the suspended particles sedimentation rate from wastewater (Doctoral Thesis). Universiti Teknologi Malaysia, Malaysia.

Su, Z., Li, X., Yang, Y., Xu, M., Ding, Y., \& Zhou, Z. (2016). Optimization of magnetic-seeding coagulation in artificially polluted surface water treatment by response surface methodology. Desalination and Water Treatment, 57, 20671-20682.

Takayasu, M., Hwang, J. Y., Friedlaender, F. J., Petrakis, L., \& Gerber, R. (1984). Magnetic separation utilizing a magnetic susceptibility gradient. IEEE Transactions on Magnetics, 20, 155-159.

Tomska, A., \& Wolny, L. (2008). Enhancement of biological wastewater treatment by magnetic field exposure. Desalination, 222, 368-373.

Ueda, H., Agatsuma, K., Kajikawa, K., Furuse, M., Fuchino, S., \& Ishiyama, A. (2009). Design and test of filter of high gradient magnetic separation system for trapping immunoglobulin in serum. IEEE Transactions on Applied Superconductivity, 19, 2157-2161.

Wang, Q., Guan, Y., Ren, X., Yang, M., \& Liu, X. (2012). Removal of low concentration Cr(VI) from aqueous solution by magnetic-fluids fixed bed using the high gradient magnetic separation. Journal of Colloid and Interface Science, 374(1), 325-330.

Zaidi, N. S., Sohaili, J., Muda, K., \& Sillanpaa, M. (2014). Magnetic field application and its potential in water and wastewater treatment systems. Journal of Separation and Purification Reviews, 43, 206-240. 
Zheng, X., Wang, Y., \& Lu, D. (2015). A realistic description of influence of the magnetic field strength on high gradient magnetic separation. Minerals Engineering, 79, 94-101.

Zheng, X., Xue, Z., Wang, Y., Zhu, G., Lu, D., \& Li, X. (2019). Modeling of particle capture in high gradient magnetic separation : A review. Powder Technology, 352, 159-169.

Zhou, Y., Nie, H., Branford-white, C., He, Z., \& Zhu, L. (2009). Removal of $\mathrm{Cu}^{2+}$ from aqueous solution by chitosan-coated magnetic nanoparticles modified with $\alpha$-ketoglutaric acid. Journal of Colloid and Interface Science, 330(1), 29-37. 
